\title{
POLIKULTUR IKAN KERAPU LUMPUR (Epinepbelus suillus) DAN BERONANG (Siganus javus) YANG DIBERI PAKAN BERBEDA DALAM HAMPANG DI TAMBAK
}

\author{
Rohama Daud"), Utojo") dan Fadlil Rasjid")
}

\begin{abstract}
ABSTRAK
Telah dilakukan penelitian pemberian jenis pakan berbeda dalam polikultur ikan kerapu lumpur (E.suillus) dan beronang (S.javus) untuk mengetahui pengaruh jenis pakan terhadap pertumbuhan dan kelangsungan hidupnya. Empat jenis perlakuan yang telah dilakukan yaitu pakan komersial atau pelet untuk ikan bandeng (A), ikan mujair (B), campuran pelet dengan ikan mujair (C) dan tanpa pakan (D).

Padat penebaran yang diaplikasikan adalah 2 ekor kerapu dan 8 ekor beronang per hampang yang berukuran $2 \times 2 \mathrm{~m}$ dengan $3 \mathrm{kali}$ ulangan untuk masing-masing perlakuan.

Jenis pakan campuran pelet dengan ikan rucah memperlihatkan pertumbuhan yang paling baik pada polikultur ikan kerapu lumpur dan beronang dengan rasio konversi pakan 2,24-3,25 untuk ikan kerapu lumpur dan 2,45-3,23 untuk ikan beronang.
\end{abstract}

\section{ABSTRACT: Polyculture of Estuary Grouper, E.swillus and siganids S.javus Fed Different Feed in Brackishwater Pond, by: Robama Daud, Utojo and Fadlil Rasjid}

Feeding trials were conducted to find out appropriate feed in the polyculture of estuary grouper, E.suillus and siganids, S.javus in $2 \times 2 \mathrm{~m}$ pens which are located in brackishwater pond. Four different trestments were evaluated i.e., commercial pelleted feed commonly used for milkfish (A), tilapia (B), mixture of pellet and tilapia (C) and without feed (D). The stocking density was two groupers and eight siganids per pen. Three replications were applied for each treatment.

Mixture of pellet and tilapia produce higher growth in both estuary grouper and siganids compared to other feeds. The range of feed conversion ratios for estuary grouper and siganids were 2.24-3.25 and 2.45-3.23, respectively.

\section{KEYWORDS: Grouper, fish ponds, feed conversion}

\section{PENDAHULUAN}

Pengembangan komoditas perairan pantai seperti ikan kerapu dan beronang mempunyai prospek yang cukup cerah, baik dilihat dari prospek pasar dan harga maupun dari prospek pembudidayaannya. Di Indonesia jenis beronang yang mempunyai harga relatif tinggi adalah Siganus canaliculatus dan Siganus guttatus. Kedua komoditas ini dapat dibudidayakan di tambak karena mempunyai sifat toleransi yang tinggi terhadap perubahan salinitas (Randall, 1965; Burhanuddin, 1987). Kecepatan pertumbuhan benih ikan beronang di alam sangat dipengaruhi oleh banyak tidaknya makanan yang disukai. Menurut Nurhakim (1984) semakin tinggi kepadatan ilalang laut (Enhalus sp.) semakin cepat pertumbuhan benih ikan beronang. Di samping itu Tacon et al. (1991) 
berpendapat bahwa ikan beronang dapat diberi pakan dalam bentuk pellet kering. Sedangkan ikan kerapu tergolong ikan buas yang rakus, sehingga menurut Boonyaratpalin (1993) pada umumnya pemeliharaan ikan kerapu dalam kurungan jaring apung menggunakan ikan rucah sebagai pakan yang harganya relatif tinggi sehingga kesinambungan pakan sangat sulit, di samping itu kualitas bervariasi dan konversi pakan kurang baik sehingga tidak ekonomis.

Dengan didasari adanya kebiasaan makan yang berbeda antara beronang dan kerapu maka dilakukan percobaan polikultur untuk melihat jenis pakan yang layak diberikan pada kedua jenis ikan tersebut.

\section{BAHAN DAN METODE}

Percobaan dilakukan di Instalasi Tambak Percobaan Marana, Maros, Sulawesi Selatan menggunakan 12 petak hampang yang masing-masing berukuran $2 \times 2 \mathrm{~m}$. Sebelum ikan ditebar, tambak dikeringkan dan dilakukan pemberantasan hama serta pemupukan. Ikan uji yang dicobakan adalah ikan kerapu lumpur (E.suillus) dengan kisaran berat 34,51-54,22 $\mathrm{g}$ dan beronang dengan kisaran berat 21,58-27,67 g. Kepadatan ikan kerapu yang dicoba adalah 2 ekor $/ 4 \mathrm{~m}^{2}$ dan beronang 8 ekor $/ 4 \mathrm{~m}^{2}$. Jenis pakan yang diuji adalah pelet untuk ikan bandeng (A), ikan mujair (B), campuran pelet dan ikan mujair (C) dan sebagai kontrol tanpa pakan (D). Jumlah pakan yang diberikan sebanyak 3-5\% per hari. Perlakuan dirancang secara acak lengkap dengan 3 kali ulangan.

Untuk penyesuaian pemberian pakan dilakukan sampling setiap 2 minggu dengan cara menimbang sebanyak 4 ekor beronang dan 2 ekor kerapu menggunakan timbangan elektrik dengan ketelitian 0,01 g. Pada akhir penelitian dilakukan perhitungan pertumbuhan mutlak dan relatif ikan uji dengan menggunakan rumus Royce (1972), kelangsungan hidup menurut Effendie (1979) dan rasio konversi pakan menurut petunjuk Sedgwick (1979) dengan asumsi bahwa pelet hanya dimakan oleh beronang dan kerapu hanya makan ikan rucah.

Sebagai data penunjang dilakukan juga pengamatan kualitas air meliputi suhu air, oksigen terlarut, bahan organik total, salinitas dan $\mathrm{pH}$.

\section{HASIL DAN PEMBAHASAN}

Hasil penelitian menunjukkan bahwa pertumbuhan mutlak, pertumbuhan relatif, kelangsungan hidup dan konversi pakan ikan uji selama 84 hari dari berbagai perlakuan sangat bervariasi (Tabel 1). Pada perlakuan pakan pelet nampak bahwa pelet yang diberikan hanya dimanfaatkan oleh ikan beronang dengan pertumbuhan relatif yang dicapai $165 \%$ sedangkan ikan kerapu hanya $3,65 \%$. Hal ini sesuai dengan pendapat Tacon et al.(1991) bahwa ikan beronang dapat tumbuh dengan baik apabila diberi pakan dalam bentuk pelet kering. Perlakuan pakan mujair memberikan pertumbuhan relatif yang tinggi untuk 
ikan kerapu (174,81\%), sedang ikan beronang hanya 59,78\%. Pada perlakuan campuran pelet dengan ikan mujair memperlihatkan pertumbuhan yang relatif tinggi untuk masing-masing komoditas, sedang perlakuan tanpa pakan pertumbuhan untuk semua ikan uji relatif rendah (Gambar 1). Pada perlakuan tanpa pakan tambahan, ikan-ikan uji masih dapat tumbuh, karena pada awal persiapan tambak tetap dilakukan pemupukan untuk menumbuhkan makanan alami berupa lumut dan jasad renik lainnya. Ranoemihardjo dan Koesnendar (1994) menjelaskan bahwa ikan beronang yang dipelihara di tambak dapat memakan lumut sutera, Cbaetomorpha spp. dan kelekap. Dari data tersebut dapat dilihat bahwa tidak ada persaingan makan di antara ikan uji sesuai dengan prinsip dasar polikultur bahwa ikan lebih dari satu jenis yang dipelihara mempunyai jenis makanan yang berbeda.

Tabel 1. Pertumbuhan mutlak, pertumbuhan relatif, kelangsungan hidup dan konversi pakan ikan beronang dan kerapu selama penelitian

Table 1. Absolut and relative growth, survival rate and feed conversion ratio of siganids and estuary grouper in a polyculture

\begin{tabular}{|c|c|c|c|c|c|}
\hline $\begin{array}{l}\text { Perlikunn } \\
\text { Treannent }\end{array}$ & $\begin{array}{l}\text { Komoditos } \\
\text { Commodity }\end{array}$ & $\begin{array}{l}\text { Pertumbuhan } \\
\text { absolut } \\
\text { Absolute } \\
\mathbf{8} \text { roupl } \\
\text { (g) }\end{array}$ & $\begin{array}{l}\text { Pertumibuhan } \\
\text { Relalatiof } \\
(\% / d)\end{array}$ & $\begin{array}{l}\text { Keluluson } \\
\text { hidup } \\
S R \\
(\%)\end{array}$ & $\begin{array}{l}\text { Konversi palan } \\
\text { Feed convertion } \\
\text { ratio }\end{array}$ \\
\hline \multirow[t]{2}{*}{ A } & Grouper & 2.11 & 3.65 & 83.3 & - \\
\hline & Siganids & 44.60 & 165.55 & 87.5 & 3.23 \\
\hline \multirow[t]{2}{*}{ B } & Grouper & 94.78 & 174.81 & 100.0 & 3.25 \\
\hline & Siganids & 12.90 & 59.78 & 100.0 & - \\
\hline \multirow[t]{2}{*}{ C } & Grouper & 88.29 & 255.84 & 50.0 & 2.24 \\
\hline & Siganids & 26.89 & 82.36 & 100.0 & 2.45 \\
\hline \multirow[t]{2}{*}{ D } & Grouper & 12.76 & 28.97 & 83.3 & - \\
\hline & Siganids & 7.19 & 25.96 & 95.83 & - \\
\hline
\end{tabular}

$A=$ pellet $\quad C=$ pellet + tilapia

$B=$ tilapia $\quad D=$ without feed

Kelangsungan hidup ikan uji kelihatannya relatif cukup tinggi yaitu 87,5\%-100\% untuk ikan beronang dan 50\%-100\% untuk ikan kerapu, akibat tidak ada pemangsaan di antara ikan uji. Adanya mortalitas disebabkan karena penanganan yang kurang baik pada waktu pengambilan sampel. Ikan kerapu yang dikenal sebagai ikan buas (Ahmad et al., 1991) tidak dapat memangsa ikan beronang mungkin karena bentuk ikan beronang yang pipih dengan sirip yang tajam sehingga susah dimangsa oleh ikan kerapu. Selain itu ikan kerapu suka menyembunyikan diri di dasar sedang ikan beronang suka berenang bergerombol di permukaan menyebabkan ikan ini sulit dimangsa. 


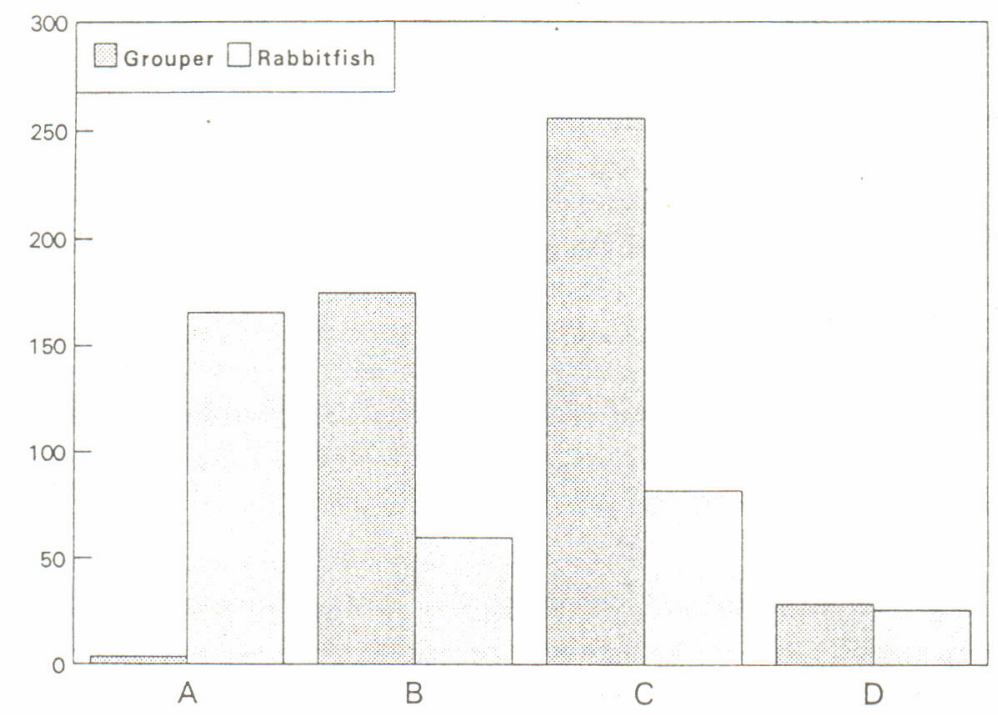

Gambar 1. Pertumbuhan relatif ikan uji untuk masing-masing perlakuan. $\mathrm{A}=$ pelet, $\mathrm{B}=$ ikan mujair, $\mathrm{C}=$ pelet + mujair, dan $\mathrm{D}=$ tanpa pakan

Figure 1. Relative growth of estuary grouper and siganids for each treatment. $A=$ pellet, $B=$ tilapia, $C=$ pellet + tilapia, $D=$ without feed

Nilai konversi pakan untuk ikan kerapu berkisar antara 2,24-3,25 menunjukkan bahwa ikan ini sangat efisien dalam menggunakan pakan. Nilai ini lebih rendah dibanding dari hasil penelitian Sugama et al. (1986) yang menyatakan bahwa ikan kerapu lumpur, E.tauvina tumbuh paling cepat dengan konversi pakannya paling rendah (pakan tembang) 5,1-8,5. Menurut Pascual (1979), makin rendah nilai konversi suatu pakan semakin baik karena jumlah pakan yang dihabiskan untuk menghasilkan berat tertentu adalah semakin sedikit.

Nilai konversi pakan untuk ikan beronang berkisar antara 2,45-3,24. Nilai ini tidak jauh berbeda dengan nilai yang didapatkan oleh Tonnek et al. (1993) yaitu 3,1 pada budidaya ikan beronang di keramba jaring apung.

Hasil pengamatan terhadap tingkah laku ikan uji menunjukkan bahwa persaingan dalam hal makanan tidak nampak sama sekali. Ikan kerapu yang hidupnya di dasar kelihatannya sangat pasif, tapi apabila ada makanan langsung diterkam. Sebaliknya ikan beronang sangat lincah berenang di permukaan secara bergerombol. Pada saat lapar mereka lebih senang berada di pinggir hampang untuk memakan lumut yang tumbuh pada dinding hampang. Hasil pengamatan kualitas air selama penelitian disajikan pada Tabel 2. 
Tabel 2. Parameter kualitas air selama penelitian

Table 2. Water quality variables during the experiment

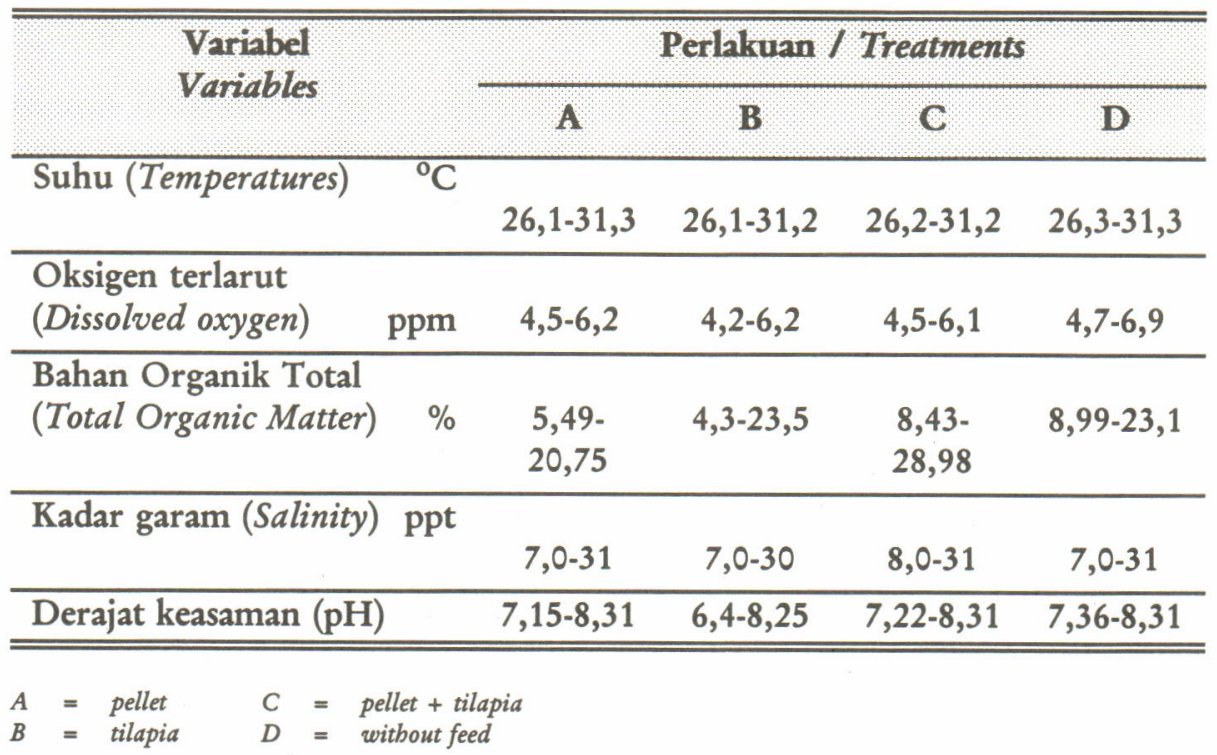

Dari pengamatan kualitas air selama penelitian nampak bahwa salinitas mempunyai kisaran yang besar. Yap (1976) berpendapat bahwa salinitas yang baik dipertahankan di tambak ialah 10-25 ppt. Di perairan tambak salinitas akan dipengaruhi oleh presipitasi, evaporasi rembesan dan bocoran, serta tipe dan lamanya pergantian air pada saat pasang dan surut. Burhanuddin (1987) melaporkan, bahwa ikan beronang dapat hidup dengan normal pada kisaran salinitas 5-35 ppt. Jadi salinitas yang didapatkan selama penelitian ini masih layak bagi kehidupan ikan beronang. Selanjutnya dijelaskan oleh Randall (1965) bahwa ikan kerapu dapat hidup pada salinitas 15-45 ppt. Pada beberapa perlakuan ditemukan adanya kematian ikan kerapu yang kemungkinan disebabkan oleh rendahnya salinitas (7 ppt) akibat turunnya hujan.

Data kualitas air lainnya masih menunjukkan batas toleransi bagi kehidupan ikan uji. Menurut Boyd dan Lichtkoppler (1979) ikan di daerah panas (tropis) tumbuh baik pada suhu antara $25-32^{\circ} \mathrm{C} . \mathrm{pH}$ 6,5-9 adalah baik untuk pertumbuhan dan reproduksi ikan (Swingle,1973), sedangkan kandungan oksigen minimum $2 \mathrm{ppm}$ sudah cukup mendukung kehidupan organisme perairan secara normal.

\section{KESIMPULAN DAN SARAN}

Jenis pakan campuran pelet dengan ikan mujair memberikan pertumbuhan relatif yang tinggi $255,84 \%$ untuk kerapu dan $82,36 \%$ untuk ikan beronang. Pakan ikan mujair saja memberikan kelangsungan hidup 100\% untuk ikan 
kerapu dan beronang dalam sistem polikultur. Konversi pakan ikan kerapu 2,24-3,25 dan ikan beronang 2,45-3,24.

\section{UCAPAN TERIMA KASIH}

Dengan selesainya laporan ini, penulis mengucapkan terima kasih kepada saudara Sutrisyani, Rosiana Sabang dan Reny Yulianingsih yang telah membantu pengamatan kualitas air selama penelitian berlangsung.

\section{DAFTAR PUSTAKA}

Boonyaratpalin M., 1993. Nutritional requirement of grouper, Epinephelus. The Proceeding of Grouper Culture. Songkhla, Thailand, 50-55 pp.

Boyd, C.E and F. Lichtkoppler, 1979. Water quality management in pond fish culture. International Centre for Aquaculture, Agriculture, Agriculture Experiment Station, Auburn University, Auburn Alabama. 30 p.

Burhanuddin, 1987. Pengaruh kadar garam air terhadap pertumbuhan dan tingkat kematian ikan beronang (S.canaliculatus). J.Penel. Budidaya Pantai, 3(2):37-48.

Effendie M.I., 1979. Metode biologi perikanan. Cetakan pertama. Yayasan Dewi Sri, Bogor.

Nurhakim S., 1984. Komposisi species benih ikan beronang (Siganus spp.) berdasarkan lingkungan hidupnya di perairan Teluk Banten. Laporan Penelitian Perikanan Laut (Marine Fisheries Research Report). Badan Penelitian dan Pengembangan Pertanian. Departemen Pertanian Jakarta. No.30 hal. 1-16.

Pascual, F.P., 1979. Aquaculture nutrition. UNDP/FAO. Network of Aquaculture Centre in Asia, Philippine Lead Centre, Tigbauan, Iloilo.

Randall, J.E., 1965. Food habits of reef fishes of the West Indies Stud. Trop. Oceanog., 5:665-847.

Ranoemihardjo, B.S dan E. Koesnendar, 1984. Budidaya ikan samadar (Siganus spp.) dalam Pedoman Budidaya Tambak. Ditjen Perikanan, Jakarta. Hal 156-177.

Royce, W.F., 1972. Introduction to the fishery sciences. Academic Press. Inc-New York-San Fransisco-London.

Sedgwick, R.W., 1979. Influence of dietary protein and energy on growth, food consumption and food conversion effisiency in Penaeus merguencis de Man. Aquaculture 16:7-30. 
Sugama, K., 1986. Studi kebiasaan makanan dan pertumbuhan benih ikan kerapu, Epinephelus tauvina dan Epinephelus morbua di Teluk Banten. Scientific Report of Mariculture Research and Development Project (ATA-192) in Indonesia. Hal. 143-149.

Sugama, K., Waspada, dan H. Tanaka, 1986. Perbandingan laju pertumbuhan beberapa jenis ikan kerapu, Epinephelus spp. dalam kurung-kurung apung. Scientific report of mariculture research and development project (ATA-192) in Indonesia (hal 143-149).

Swingle, H.S., 1963. Methods of analysis for water, organic matter and pond bottom soils. Auburn University, Auburn, Alabama

Tacon, A.G.J, Nur Rausin dan M.Kadari, 1991. Pengaruh pemberian jenis pakan yang berbeda terhadap pertumbuhan ikan beronang (S.canaliculatus) di kurungan apung. Bulletin Bud. Laut. No.3:15-22.

Tonnek, S., D.S.Pongsapan, dan Rachmansyah, 1993. Polikultur nila merah dan beronang dalam keramba jaring apung. J. Pen. Budidaya Pantai, 9(3):47-54.

Yap, W.G., 1976. Physical aspects of water importance to aquaculture. In Special training on pond construction ang management for pond owners of Zamboanga and Cotabato. BFAR. Western Visayas Federation of Fish Producers. Aquaculture Department Seafdec. Sept-Oct, 1976. Philippines p:122-128. 